\title{
Editorial
}

\section{Fiber-Reinforced Composites for Dental Applications}

\author{
Andrea Scribante $\mathbb{D}^{1}{ }^{1}$ Pekka K. Vallittu $\mathbb{D}^{2,3}$ and Mutlu Özcan ${ }^{4}$ \\ ${ }^{1}$ Unit of Orthodontics and Pediatric Dentistry, Section of Dentistry, Department of Clinical, Surgical, \\ Diagnostic and Pediatric Sciences, University of Pavia, Italy \\ ${ }^{2}$ Department of Biomaterial Science and Turku Clinical Biomaterials Centre (TCBC), Institute of Dentistry, \\ University of Turku, Turku, Finland \\ ${ }^{3}$ City of Turku, Welfare Division, Turku, Finland \\ ${ }^{4}$ University of Zurich, Center for Dental and Oral Medicine, Dental Materials Unit, \\ Clinic for Fixed and Removable Prosthodontics and Dental Materials Science, Zurich, Switzerland
}

Correspondence should be addressed to Andrea Scribante; andrea.scribante@unipv.it

Received 28 August 2018; Accepted 19 September 2018; Published 1 November 2018

Copyright (C) 2018 Andrea Scribante et al. This is an open access article distributed under the Creative Commons Attribution License, which permits unrestricted use, distribution, and reproduction in any medium, provided the original work is properly cited.

Fiber-reinforced composites (FRCs) are composite materials with three different components: the matrix (continuous phase), the fibers (dispersed phase), and the zone in between (interphase). FRC materials present high stiffness and strength per weight when compared with other structural materials along with adequate toughness. FRCs have been used for numerous applications in various engineering and biomedical fields for a long time. The reinforcement of dental resins with either short or long fibers on the other hand has been described in literature for more than 40 years [1]. FRCs based on carbon, polyaramid, polyethylene, and glass have been largely studied and among all, glass fibers of various compositions are more commonly applied as restorative and prosthetic materials [2, 3].

FRCs have been intensively investigated with a particular emphasis on mechanical properties such as fracture toughness, compressive strength, load-bearing capacity [4], flexural strength [5], fatigue resistance [6], fracture strength [7] or on the effect of layer thickness [8], bacterial adhesion [9], adhesion of fibers for various dental applications, such as long fibers [10], nets [11], and posts [12]. From clinical perspective, FRCs have been investigated for different clinical applications in prosthodontics, such as replacement of missing teeth by resin-bonded adhesive fixed dental prostheses of various kinds [13], reinforcement elements of dentures or pontics [14], and direct construction of posts and cores [15]. In other disciplines of dentistry, such as orthodontics FRCs have been suggested as active and passive orthodontic applications (i.e., anchorage or en-masse movement units) and postorthodontic tooth retention [16] and in periodontology for splinting mobile teeth in an attempt to prolong tooth extraction [17].

With the introduction of new technologies, nanofillers, resin matrices, fibers, adhesion protocols, and application techniques, the design principles of FRC devices need further understanding which open new fields of research both preclinically and clinically [18]. On the basis of these considerations, BioMed Research International prepared the present special issue in an attempt to explore these new variables related to FRCs.

Guest editors do hope that this special issue would be interesting for the readers of the journal and wish that the present work could help both clinicians and researchers to understand FRC applications and properties.

\section{Conflicts of Interest}

Authors Andrea Scribante and Mutlu Özcan declare that there are no conflicts of interest regarding the publication of this paper. Author Pekka K. Vallittu consults Stick Tech-GC in $\mathrm{RD}$ and training.

\section{Acknowledgments}

Finally, guest editors would like to thank the Editorial Board of BioMed Research International for the invitation to 
prepare this special issue. A special thank is also addressed to Sam Rose for kind suggestions during call for papers and to Sara Ashraf for excellent assistance during manuscript management track.

\section{Andrea Scribante Pekka K. Vallittu Mutlu Özcan}

\section{References}

[1] H. Miyairi, M. Nagai, and A. Muramatsu, "Studies on mechanical properties of denture base material laminated with organic fiber reinforced plastics. Part I. Basic consideration of hybrid construction," Bulletin of Tokyo Medical and Dental University, vol. 22, no. 4, pp. 273-280, Dec 1975.

[2] R. Seemann, M. Marincola, D. Seay, C. Perisanidis, N. Barger, and R. Ewers, "Preliminary results of fixed, fiber-reinforced resin bridges on four $4-\times 5$-mm ultrashort implants in compromised bony sites: A pilot study," Journal of Oral and Maxillofacial Surgery, vol. 73, no. 4, pp. 630-640, 2015.

[3] J. Tanner, M. Tolvanen, S. Garoushi, and E. Säilynoja, “Clinical Evaluation of Fiber-Reinforced Composite Restorations in Posterior Teeth - Results of 2.5 Year Follow-up," The Open Dentistry Journal, vol. 12, no. 1, pp. 476-485, 2018.

[4] A. Agrawal and K. Mala, "An in vitro comparative evaluation of physical properties of four different types of core materials," Journal of Conservative Dentistry, vol. 17, no. 3, pp. 230-233, 2014.

[5] V. Cacciafesta, M. F. Sfondrini, A. Lena, A. Scribante, P. K. Vallittu, and L. V. Lassila, "Flexural strengths of fiber-reinforced composites polymerized with conventional light-curing and additional postcuring," American Journal of Orthodontics and Dentofacial Orthopedics, vol. 132, no. 4, pp. 524-527, 2007.

[6] D. L. S. Foek, E. Yetkiner, and M. Özcan, "Fatigue resistance, debonding force, and failure type of fiber-reinforced composite, polyethylene ribbon-reinforced, and braided stainless steel wire lingual retainers in vitro," The Korean Journal of Orthodontics, vol. 43, no. 4, pp. 186-192, 2013.

[7] O. Kumbuloglu, M. Özcan, and A. User, "Fracture strength of direct surface-retained fixed partial dentures: Effect of fiber reinforcement versus the use of particulate filler composites only," Dental Materials, vol. 27, no. 2, pp. 195-202, 2008.

[8] J. Bijelic-Donova, S. Garoushi, L. V. J. Lassila, and P. K. Vallittu, "Oxygen inhibition layer of composite resins: effects of layer thickness and surface layer treatment on the interlayer bond strength," European Journal of Oral Sciences, vol. 123, no. 1, pp. 53-60, 2015.

[9] B. Akalin-Evren, Y. Kulak-Özkan, M. Özcan, and T. Kadir, "Candida albicans adhesion on reinforced polymethylmethacrylate denture resin: Effect of fibre architecture and exposure to saliva," Gerodontology, vol. 31, no. 3, pp. 194-201, 2014.

[10] A. Scribante, V. Cacciafesta, and M. F. Sfondrini, "Effect of various adhesive systems on the shear bond strength of fiberreinforced composite," American Journal of Orthodontics and Dentofacial Orthopedics, vol. 130, no. 2, pp. 224-227, 2006.

[11] M. F. Sfondrini, V. Cacciafesta, and A. Scribante, "Shear bond strength of fibre-reinforced composite nets using two different adhesive systems," European Journal of Orthodontics, vol. 33, no. 1, pp. 66-70, 2011.
[12] A. Sharma, F. Samadi, J. Jaiswal, S. Saha, and N. Marwah, "A Comparative Evaluation of Effect of Different Chemical Solvents on the Shear Bond Strength of Glass Fiber reinforced Post to Core Material," International Journal of Clinical Pediatric Dentistry, vol. 7, pp. 192-196, 2014.

[13] A. I. Karaman, N. Kir, and S. Belli, "Four applications of reinforced polyethylene fiber material in orthodontic practice," American Journal of Orthodontics and Dentofacial Orthopedics, vol. 121, no. 6, pp. 650-654, 2002.

[14] S. Garoushi and S. Patil, "Single Visit Replacement of Maxillary Canine using Fiber-reinforced Composite Resin," The Journal of Contemporary Dental Practice, pp. 125-129, 2013.

[15] S. Murali Mohan, E. Mahesh Gowda, and M. P. Shashidhar, "Clinical evaluation of the fiber post and direct composite resin restoration for fixed single crowns on endodontically treated teeth," Medical Journal Armed Forces India, vol. 71, no. 3, pp. 259-264, 2015.

[16] A. Scribante, M. F. Sfondrini, S. Broggini, M. D’Allocco, and P. Gandini, "Efficacy of esthetic retainers: clinical comparison between multistranded wires and direct-bond glass fiberreinforced composite splints," International Journal of Dentistry, vol. 2011, Article ID 548356, 5 pages, 2011.

[17] O. Kumbuloglu, A. Saracoglu, and M. Özcan, "Pilot study of unidirectional E-glass fibre-reinforced composite resin splints: Up to 4.5-year clinical follow-up," Journal of Dentistry, vol. 39, no. 12, pp. 871-877, 2011.

[18] M. F. Sfondrini, S. Massironi, G. Pieraccini et al., "Flexural strengths of conventional and nanofilled fiber-reinforced composites: a three-point bending test," Dental Traumatology, vol. 30, no. 1, pp. 32-35, 2014. 


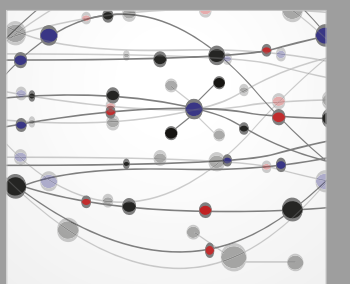

The Scientific World Journal
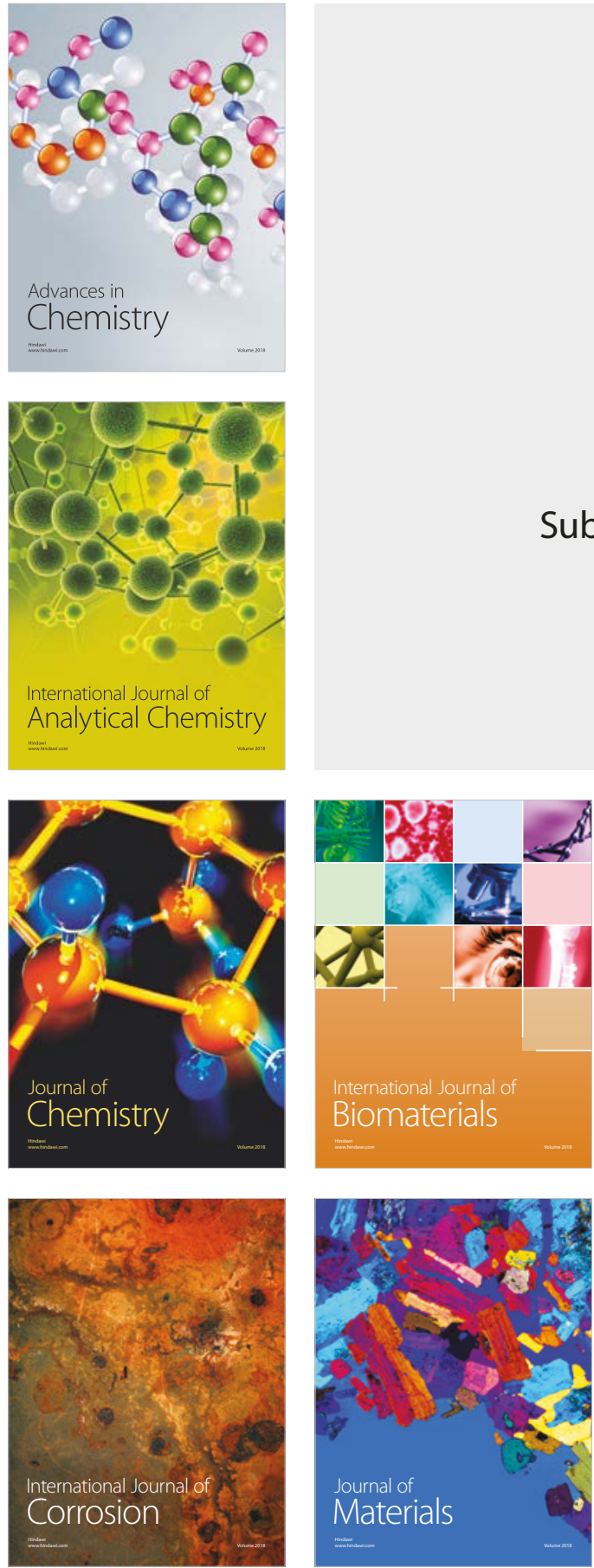

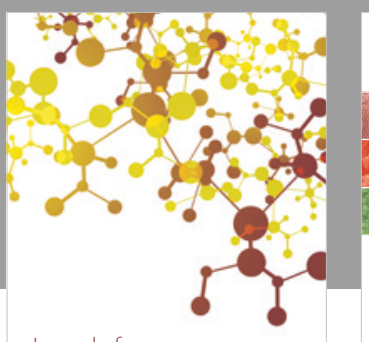

Journal of

Applied Chemistry
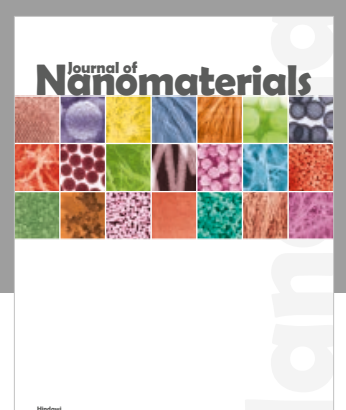

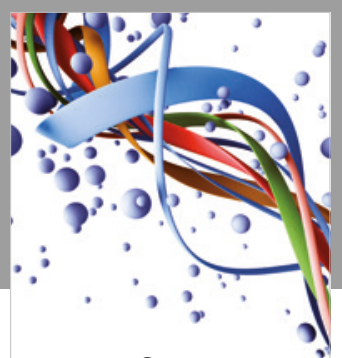

Scientifica

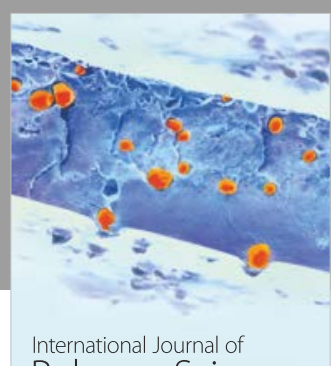

Polymer Science

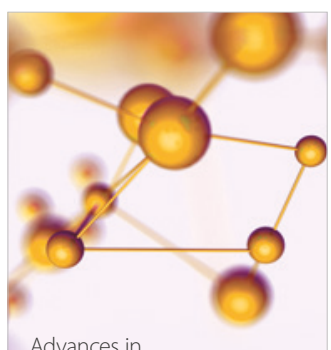

Physical Chemistry
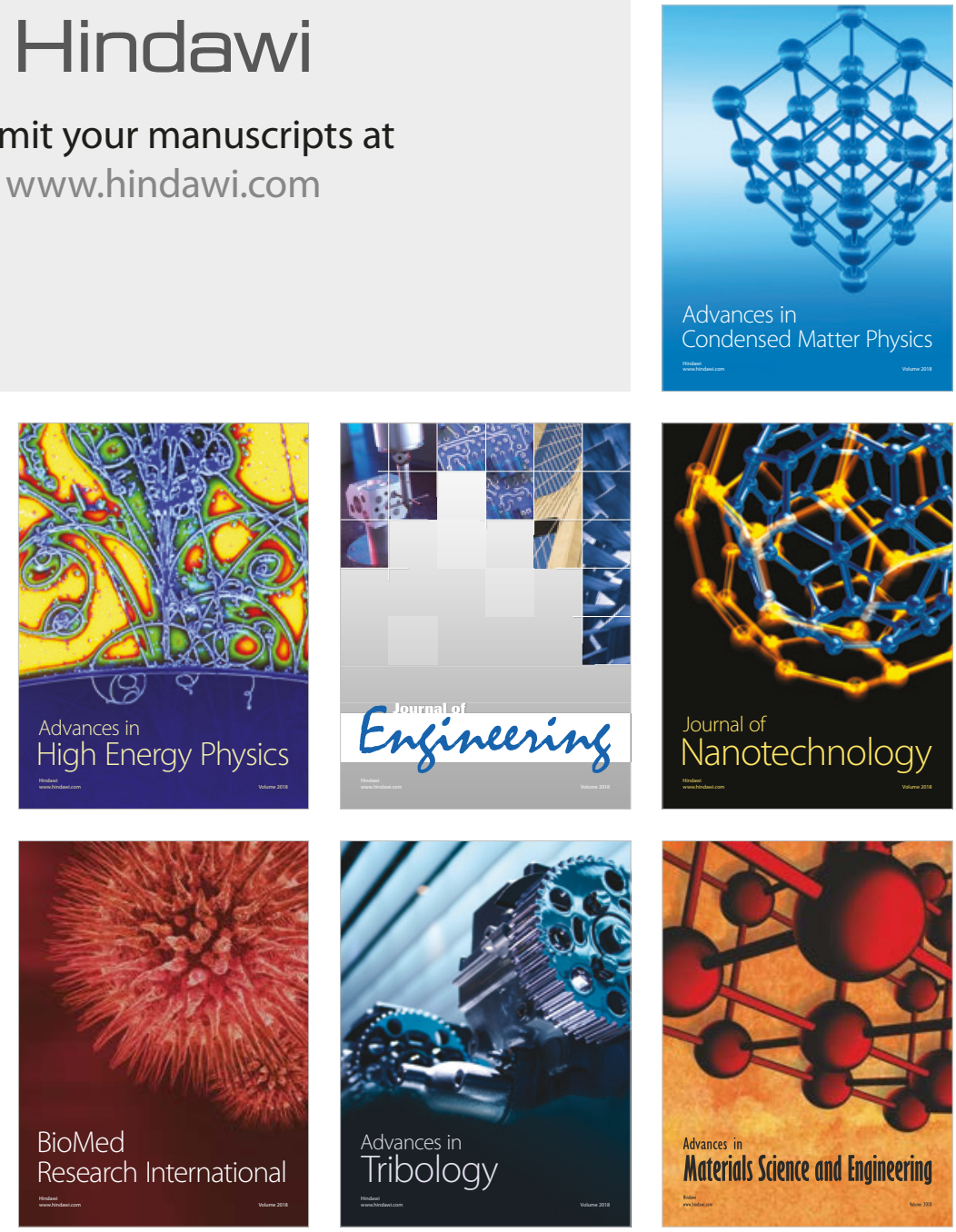